\title{
Risk analysis and exposure assessment of Ochratoxin A in Serbia
}

\author{
Dragan R. Milićević, Srđan Stefanović, Saša Janković, Tatjana Radičević
}

Institute of Meat Hygiene and Technology,

Kaćanskog 13, 11000 Belgrade, Serbia

Corresponding author: Dragan R. Milićević, email: dragan@inmesbgd.com,

Tel: +381112650655, fax: +381112651825

Received:12-12-2011, Accepted: 27-01-2012, Published Online: 11-04-2012

doi: $10.5455 /$ vetworld.2012.412-416

\begin{abstract}
Aim: The aim of this study was to check the current status of OTA contamination of the Serbian pork and chicken meat in naturally exposed animals which are part of chain production. The knowledge of these factors, their importance and significance, can be used as a tool from the food safety point of view to predict if OTA content in pork and chicken tissues poses a risk to human health and deleterious effects on animals' health and well-being.

Materials and Methods: A total of 540 samples of pigs blood, kidney, liver and chicken gizzard were randomly selected from slaughtered pigs $(n=90)$ and chicken $(n=90)$ and analyzed for the presence of ochratoxin $A(O T A)$ by High-performance liquid chromatography (HPLC-FL).

Results: In porcine tissue samples, of the 90 liver samples, $26.6 \%$ contained OTA in the range of $0.22-14.5 \mathrm{ng} / \mathrm{g}$. The incidence of OTA in serum and kidneys were very similar (31\% and 33.3\%, respectively), with a maximum concentration of $220.8 \mathrm{ng} / \mathrm{mL}$, and $52.5 \mathrm{ng} / \mathrm{g}$, respectively. Majority of chickens' tissues samples, were not found to contain measurable amounts of OTA. Moreover, the OTA levels found in analysed tissues were low in general.

Conclusion: The results of this preliminary research indicate that the content of OTA in the examined tissues are far below the values that represent hazard to the health of consumers. However, the results of this study show that in Serbia, consumers are nevertheless frequently exposed to ochratoxins.

Key words: ochratoxin A, tissues samples, residue, exposure assessment
\end{abstract}

\section{To cite this article:}

Milićević* DR, Stefanović S, Janković S, Radičević T (2012) Risk analysis and exposure assessment of Ochratoxin A in Serbia, Vet World, 5(7):412-416, doi: 10.5455/vetworld.2012.412-416

\section{I ntroduction}

Undesirable substances such as mycotoxins can be present in plants and derived products thereof. Depending on the nature and the concentration levels of the compound, these might be of concern for human and/or animal health. From the more than 300 mycotoxins isolated and described to the present day, OTA is recognized as a contaminant with a strong nephrotoxic activity [1]. The International Agency for Research on Cancer has classified OTA as possibly carcinogenic for humans (group 2B) [2], also teratogenic and carcinogenic effects have been described in some animal species [3].

Ochratoxin A is a secondary metabolite of fungi such as Penicillium verrucosum and Aspergillus ochraceus that occur in a number of food commodities like cereals, coffee, dried fruit, pulses, and derivates products [4]. Apart from cereals products, that are considered to be the most contaminated samples, meat and meat products are also frequently contaminated with OTA due to carry-over effect. Kidney is the most contaminated organ, followed by pig blood, liver, and meat from animals fed with contaminated feed [5-8]. Through the food chain OTA can appear in human fluids, such as plasma [9], urine [10] and milk [11].

Exposure to OTA is a potential human health hazard because of the frequent exposure, long-half life in the organism and its carcinogen properties in experimental animals. The risk is well recognized, but at present it has not been quantified accurately. In some Eastern European countries (in particular Bulgaria, Romania, Serbia, Croatia, Bosnia and Herzegovina) OTA has been associated with a high incidence of a kidney disease known as Balkan endemic nephropathy [12]. Consumption of foods contaminated with OTA during pregnancy and/or childhood is suspected of inducing lesions in testicular 
DNA which, during puberty, can be promoted to testicular cancer [13]. Indeed, rates of incidence of testicular cancer in 20 countries correlated significantly with the per-capita consumption of coffee and pig meat. The dietary intake of OTA by the population of EU member states has been assessed and the Joint FAO/WHO Expert Committee on Food Additives (JEFCA) has recently established a provisional tolerable weekly intake of $100 \mathrm{ng} / \mathrm{kg} \mathrm{b.w}$. per week [14].

Moreover, poultry and pork meat comprises a substantial portion of the Serbian diet $(17.4 \mathrm{~kg}$ and 16 $\mathrm{kg}$, respectively, per person in 2009). The aim of this study was to check the current status of OTA contamination of the Serbian pork and chicken meat in naturally exposed animals which are part of chain production. The knowledge of these factors, their importance and significance, can be used as a tool from the food safety point of view to predict if OTA content in pork and chicken tissues poses a risk to human health and deleterious effects on animals' health and wellbeing.

\section{Materials and methods}

Samples collection: Pilot study was carried out during 2009 and 2010. Swine and poultry commercial farms in the northem and central agricultural area of Serbia were randomly selected. Pigs and chicken were selected randomly in slaughterhouses that are important for overall meat production, at the end of fattening week, by random method. About $50 \mathrm{~mL}$ of blood per pig was sampled by jugular puncture. Blood samples remained at room temperature for $24 \mathrm{~h}$ to allow for clotting, and were subsequently centrifuged at $3,000 \times g$ for $20 \mathrm{~min}$. Serum was decanted and stored at $-20^{\circ} \mathrm{C}$ prior to analysis. Whole liver, kidney and gizzard (chickens) were sampled from each animals. No preservatives were added. A total of 540 samples of serum samples (pigs), liver, kidneys and gizzard (chickens) from slaughtered pigs $(n=90)$ and chicken ( $n=90)$ were collected.

Chemical and Reagents: Ochratoxin A crystalline material was purchased from Sigma (St. Louis, MO, USA). Stock concentrated solution was prepared in toluene-acetic acid $(99: 1 \mathrm{v} / \mathrm{v})$ at a final concentration of $1 \mathrm{mg} / \mathrm{mL}$ and kept in security conditions at $-20^{\circ} \mathrm{C}$, wrapped in aluminum foil, because OTA gradually breaks down under ultraviolet light. The OTA working solution was prepared by diluting the stock solution with toluene-acetic acid (99:1 v/v) to $\sim 10 \mu \mathrm{L} / \mathrm{mL}$. The actual concentration of OTA was calculated using the absorbance by the UV spectrophotometer set at 333 $\mathrm{nm}(=5550)$. After suitable dilutions by watermethanol-acetic acid (50:49:1 v/v/v), the working solution was used to prepare the external calibration curve. A working standard OTA for HPLC was prepared daily just before starting the injection of a series of samples. Other reagents were of HPLC grade. All chemicals were of HPLC grade, reagent grade or chemically pure.

Extraction and clean-up for ochratoxin analyses: Serum $(0.8 \mathrm{~mL})$ was extracted according to Curtui and Gareis (2001) [15] with $15 \%$ trichloroacetic acid (0.2 $\mathrm{mL})$ and dichloromethane $(1 \mathrm{~mL})$, by vigorous vortexing for $30 \mathrm{~s}$ in a $2 \mathrm{~mL}$ safe-lock polypropylene conical-bottom centrifuge tube. The mixture was allowed to stand for $24 \mathrm{~h}$ at room temperature, and then centrifuged at $14,000 \times \mathrm{g}$ for $10 \mathrm{~min}$. The lower dichloromethane phase was carefully withdrawn by a Pasteur pipette and transferred to a $1.5 \mathrm{~mL}$ safe-lock polypropylene conical bottom centrifuge tube. The acidic phase and the compact precipitate layer formed between the two phases were re-extracted with dichloromethane $(0.5 \mathrm{~mL})$ for $30 \mathrm{~s}$ on a vortex mixer and then centrifuged for $5 \mathrm{~min}$ at $14,000 \times \mathrm{g}$. The pooled dichloromethane extract was evaporated to dryness at $40{ }^{\circ} \mathrm{C}$ under a gentle nitrogen flow. The remaining residue was reconstituted in methanol (500 $\mu \mathrm{L})$ and transferred to a HPLC vial. The limit of detection (signal/noise: 3/1) was estimated at 0.1 $\mathrm{ng} / \mathrm{mL}$ of OTA, and average recovery was $95 \%$.

Kidney, gizzard and liver analyses were performed by the method of Matrella et al. [16], which briefly includes a double extraction with acidic ethyl acetate. The organic phase was removed and extracted with $0.5 \mathrm{M} \mathrm{NaHCO}, \mathrm{pH}$ 8.4. The aqueous extract was acidified to $\mathrm{pH} 2.5$ with $7 \mathrm{M}$ orto-phosphoric acid. OTA was finally back extracted into ethyl acetate (3 $\mathrm{mL}$ ). The organic phase was evaporated to dryness under $\mathrm{N}_{2}$ steam, reconstituted in $500 \mu \mathrm{L}$ of mobile phase and a $50 \mu \mathrm{L}$ of aliquot was injected. The detection limit for OTA in organs was $0.01 \mathrm{ng} / \mathrm{g}$ with $61 \%$ (C.V. $=14.5 \%$ ) mean recovery from fortified samples at $3 \mathrm{ng} / \mathrm{g}(\mathrm{n}=3)$.

Chromatographic conditions (HPLC): An aliquot of $20 \mu \mathrm{L}$ for serum samples, $50 \mu \mathrm{L}$ for kidney, gizzard and liver samples, and for the standards $10 \mu \mathrm{L}$, were injected onto a Waters Symmetry Shield RP(Reversed phase) 18 , high pressure liquid chromatography column (length and inner diameter $150 \times 4.6 \mathrm{~mm}$, particle size $5 \mu \mathrm{m}$ ) on a Waters Alliance 2695 HPLC system. The OTA was eluted with $4 \%$ acetic acid and acetonitrile $(32: 68 \mathrm{v} / \mathrm{v})$ at $25^{\circ} \mathrm{C}$ and a flow rate of $1 \mathrm{~mL} / \mathrm{min}$. 
Risk analysis and exposure assessment of Ochratoxin A in Serbia

Table-1. Incidence and the mean concentration of ochratoxin A in tissues of slaughtered animals

\begin{tabular}{|c|c|c|c|c|c|c|}
\hline & \multicolumn{3}{|c|}{ Pig tissues $(\mathrm{N}=90)$} & \multicolumn{3}{|c|}{ Chickens tissues $(\mathrm{N}=90)$} \\
\hline & Serum $(\mathrm{ng} / \mathrm{mL})$ & Liver $(n g / g)$ & Kidneys (ng/g) & Liver $(\mathbf{n g} / \mathrm{g})$ & Kidneys (ng/g) & Gizzard (ng/g) \\
\hline LLOD n (\%) & $62(68.8)$ & 66 (73.3) & $60(66.6)$ & $67(74.4)$ & $73(81.1)$ & 75 (83.3) \\
\hline$\overline{\mathrm{x}}^{1} \pm \mathrm{Sd}$ & $3.69 \pm 23.59$ & $0.64 \pm 1.87$ & $1.24 \pm 5.89$ & $0.41 \pm 0.92$ & $0.36 \pm 1.18$ & $0.36 \pm 1.49$ \\
\hline$x_{2} \pm S d$ & $11.87 \pm 41.64$ & $2.14 \pm 2.93$ & $4.14 \pm 10.24$ & $1.62 \pm 1.16$ & $1.19 \pm 2.16$ & $2.18 \pm 3.13$ \\
\hline Range & $0.24-220.8$ & $0.18-14.5$ & $0.17-52.5$ & $0.14-3.90$ & $0.1-7.02$ & $0.25-9.94$ \\
\hline $\mathrm{CV} \%$ & 6.39 & 2.92 & 4.72 & 2.24 & 3.27 & 4.14 \\
\hline
\end{tabular}

$\mathrm{N}$-total number of analyzed samples, n- number of samples <LOD (limit of detection, see Materials and methods), $\mathrm{X}_{1}$ arithmetic mean (conc. below LOD are regarded as zero) in all of analyzed samples, $\mathrm{X}_{2}$-arithmetic mean in samples where OTA was detected, C.V.-coeff. of variation ${ }^{*}(x 100)$.

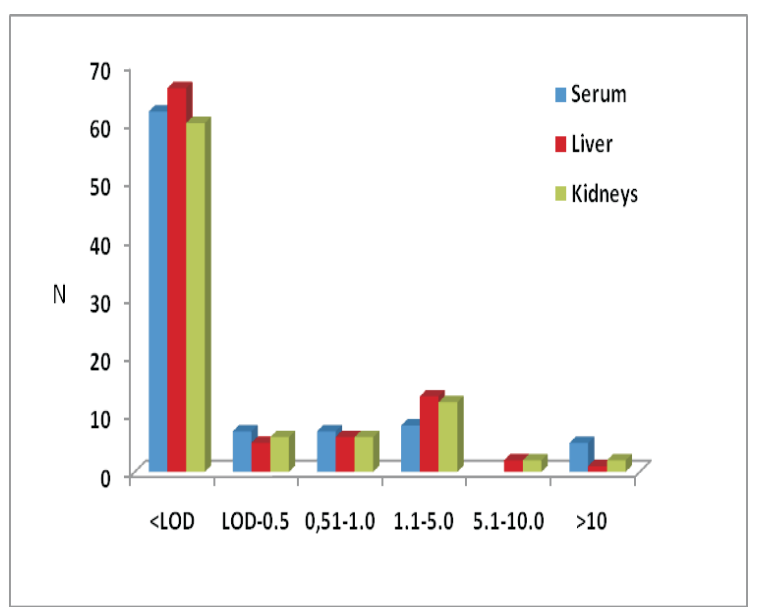

Figure 1. Distribution of OTA content in tissues of slaughtered pigs $(\mathrm{ng} / \mathrm{mL}, \mathrm{ng} / \mathrm{g}), \mathrm{N}$-number of samples, LOD (limit of detection, see Materials and methods)

Measurements were performed by fluorescence detection at wavelengths of $334 \mathrm{~nm}$ (excitation) and $460 \mathrm{~nm}$ (emission), detector gain was set to 10 . For more accuracy, $40 \mu \mathrm{L}$ of the serum samples, was reinjected in the case of the samples with an amount of OTA near the detection limit.

Statistical analysis: Descriptive data are presented as means, standard deviation (SD), and range, for continuous variables. Statistical differences in the mean levels of OTA contamination across the three groups of positive samples were determined by oneway ANOVA $(p<0.05)$. Significance was set at $p<0.05$.

\section{Results}

A total of 540 tissues samples were analysed, 270 samples per pigs and 270 chickens, for the presence of OTA. The incidence of contamination, on serum, liver, kidneys and gizzard, by OTA is summarized in Table 1, Figure 1 and 2. Of the 90 liver, kidneys and gizzard samples, respectively, originating

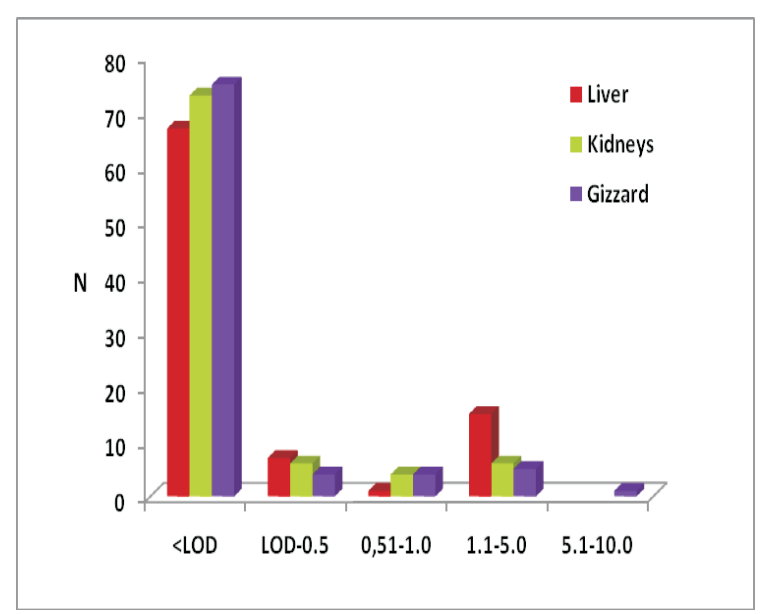

Figure 2. Distribution of OTA content in tissues of slaughtered chicken $(\mathrm{ng} / \mathrm{g}), \mathrm{N}$-number of samples, LOD (limit of detection, see Materials and methods)

from chicken farms located in the different area of Serbia, OTA was reported in 23 (25.6\%), 17 (18.9\%) and $15(16.7 \%)$ samples, respectively. The data in Table 1 show that majority (215) of these samples did not contain ochratoxin A and the rest largely had concentrations close to the detection limit. OTA levels in liver were slightly higher than those in kidneys and gizzard, but this difference was not statistically significant $(\mathrm{p}<0.05)$.

The average level of OTA in liver was $0.41 \pm$ $0.92 \mathrm{ng} / \mathrm{g}$ (range 0.14-3.9 ng/g), whereas OTA average value in kidneys and gizzard were $0.36 \pm 1.18 \mathrm{ng} / \mathrm{g}$ (range 0.1 to $7.02 \mathrm{ng} / \mathrm{g}$ ), and $0.36 \pm 1.49 \mathrm{ng} / \mathrm{g}$ (range $0.25-9.94 \mathrm{ng} / \mathrm{g}$ ) respectively. The high values of the standard deviation is due to two samples in kidneys, and one in gizzard that showed a concentration of OTA up to $7.02 \mathrm{ng} / \mathrm{g}$ and $9.5 \mathrm{ng} / \mathrm{g}$, respectively (Fig. 2). All the analyzed tissues samples were below the limit established by JECFA (10 ng/g) [14]. Only one sample of gizzard contained OTA (9.94 ng/g), close to the maximum permissible levels of this toxin proposed by 
the JECFA.

In the case of the OTA content in pigs tissues, OTA was detected in most frequently $(33,4 \%)$ in kidney samples, whereas OTA was present in $31.2 \%$ and $26.7 \%$ of serum and liver samples, respectively. With regards to the concentrations of OTA, the highest level $(220.8 \mathrm{ng} / \mathrm{mL})$, was detected in serum samples. One samples of kidneys had $52.5 \mathrm{ng} / \mathrm{g}$ OTA, while maximum level of OTA in liver was $14.5 \mathrm{ng} / \mathrm{g}$ (Fig. 1). In $2.2 \%$ samples of kidneys, OTA levels was considerably higher and greatly exceed the permissible levels of this toxins established in Serbia and included those proposed $(10 \mathrm{ng} / \mathrm{g})$ by the Scientific Committee on Food [17], and JECFA [14].

\section{Discussion}

The exposure assessment was performed by a point-estimate deterministic approach, which is an evaluation built by combining concentration single levels, or mean contamination values, of analytes with food consumption data and divided by the body weight. In this study the Tolerable Daily Intake (TDI), calculated as nanograms of ochratoxin A per kilogram of body weight per week ( $\mathrm{ng} / \mathrm{kg}$ bw/daily), was evaluated using the equation; $\mathrm{CM} \times \mathrm{P} / \mathrm{M}$.

$\mathrm{CM}$ is the concentration of mycotoxin in tissues (ng/g), $\mathrm{P}$ is the meat consumption (g/day), $\mathrm{M}$ is the mass of "average consumer" ( $60 \mathrm{~kg}$ body weight) [18].

Results found in this study suggest that, in general, OTA contamination in chicken meat originating from different part of Serbia is low, hence for the consumer the contribution to the total intake of ochratoxin A from chicken products is very small compared to other sources $(0.28 \mathrm{ng} / \mathrm{kg}$ b.w. to 0.32 $\mathrm{ng} / \mathrm{kg}$ b.w). Of 270 chicken tissues samples tested, measurable amounts of OTA were found in $55(20.3 \%)$ tissues samples, wheres incidence of OTA in pigs tissues were higher, which accounts for $30.3 \%$ of all samples. Comparison the data obtained in this trial with other recently published data for the occurrence of OTA in pig edible tissues shows that the found levels are comparable with levels in other European countries, therefore the estimated daily intake of OTA through pork meat by a $60 \mathrm{~kg}$ adult is $0.46 \mathrm{ng} / \mathrm{kg} \mathrm{b.w}$. to $0.90 \mathrm{ng} / \mathrm{kg}$ b.w. respectively.

Currently, Ochratoxin A is receiving increasing attention for its toxic effects on human health and high incidence in a wide range of food commodities. Although the ochratoxin A amounts detected in meat from Serbia were relatively low, the levels may accumulate in the body of humans consuming contaminated food. Ochratoxin A is often not rapidly removed from the body and it is frequently found in human blood due to its long elimination half-life (about 35 days in serum), as a consequence of its binding to plasma proteins, its enterohepatic circulation and its reabsorption from urine [19]. This makes of ochratoxin A the most detected mycotoxin in human blood all over the world [20]. Therefore, public health authorities in Serbia pay attention to ochratoxin A particularly by monitoring food and feedstuffs. At present, Serbia has not a maximum tolerable limits for ochratoxin A in meat and meat products, particularly pork meat. However, there is a tendency of authorities in Serbia to adopt the European Union limits for this mycotoxin.

\section{Conclusion}

The study provides the necessary knowledge information for updating the level of OTA exposure for the target products. Despite the limited number of samples examined in the present study, it is important to notice that even the low levels of OTA concentration found in tissues of slaughtered animals, may contribute to the OTA daily intake. On the basis of the risk assessment carried out in this study, the exposure to OTA, due to the consumption of pork and chicken products, is to be considered not a major concern. Therefore, it could be concluded that data arising from this study, adequate to align national legislation with the EU provisions. However, it should be remembered when align that factors such as climate conditions during harvest, practices for grain/feed storage etc have influence on the ochratoxin A level in edible tissues. Additionally, the study emphasized the role of management practices in the prevention of mycotoxin prevalence in animls farms. To protect consumer health and to reduce economic losses, surveillance and control of mycotoxins in food and feed has become a major objective for producers, regulatory authorities and researchers worldwide.

\section{Acknowledgements}

This study was funded by the Ministry of Education and Science, Belgrade, Serbia (project code TP-31008). We are grateful to the Ministry for their understanding and support to veterinary development.

\section{Competing interest}

Authors declare that they have no Competing interest.

\section{References}

1. Schaaf G. J., Nijmeijer J. M., Mass R. F. M., Roestenberg P., de Groene E. M., Fink-Gremmels J. (2002). The role of oxidative stress in Ochratoxin A- mediated toxicity in proximal tubular cells. Biochi 
Biophy Acta., 1588: 149-158.

2. IARC. (1993). Ochratoxin A. Some Naturally Occurring Substances: Food Items and Constituents, Heterocyclic Aromatic Amines and Mycotoxins. In: IARC Monograph on the evolution of carcinogenic risks to humans, Vol. 56. International Agency for Research on Cancer, Geneva, pp. 489-521.

3. Lioi M. B., Santoro A., Barbieri R., Salzano S., Ursini M. V. (2004). Ochratoxin A and Zearalenone: A comparative study on genotoxic effects and cell death induced in bovine lymphocytes. Mutat Res., 557: 19-27.

4. Beretta B., De Domenico R., Gaiaschi A., Ballabio C., Galli C. L., Gigliotti C., et al. (2002). Ochratoxin A in cereal-based baby foods: Occurrence and safety evaluation. FoodAddit Contam., 19(1): 70-75.

5. Milićević D., (2009a). Mycotoxins in the food chain -old problems and new solutions. Tehnologija mesa, 50. (1-2): 99-111.

6. Milićević D., Nikšić M., Baltić T., Stefanović S., Janković S. (2009b). The presence of molds and mycotoxins in feed for pigs-the importance of risk assessment. Tehnologija mesa, 50, (5-6): 261-270.

7. Milićević D., Jurić V., Stefanović, S., Baltić T., Janković, S. (2010a). Evaluation and Validation of Two Chromatographic Methods (HPLC-Fluorescence and LC-MS/MS) for the Determination and Confirmation of Ochratoxin A in Pig Tissues. Arch Environ Contam Toxicol., 58, (4): 1074-1081. DOI 10.1007/s00244-009-9436-2.

8. Milićević D., Nikšić M., Baltić T., Vranić D. (2010b). Isolation, characterization and evaluation of significant mycoflora and mycotoxins in pig feed from Serbian farms. World J, Microbiol, Biotechnol., 26, (9): 1715-1720, DOI: 10.1007/s11274-010-0341-7.

9. Muñoz K., Vega M., Rios G., Muñoz S., \& Madariaga R. (2006). Preliminary study of Ochratoxin A in human plasma in agricultural zones of Chile and its relation to food consumption. Food Chem Toxicol., 44: $1884-1889$.

10. Domijan A. M., Peraica M., Miletic-Medved M., Lucic A., \& Fuchs R. (2003). Two different clean-up procedures for liquid chromatographic determination of Ochratoxin A in urine. J Chromatogr., B, 798: $317-321$
11. Skaug M. A., Helland I., Solvoll K., Saugstad O. D. (2001). Presence of Ochratoxin A in human milk in relation to dietary intake. Food Addit Contam., 18(4): 321-327.

12. Pfohl-Leszkowicz A, Petkova-Bocharova T, Chernozemsky IN, Castegnaro M. (2002). Balkan endemic nephropathy and the associated urinary tract tumours: review on etiological causes, potential role of mycotoxins. Food Addit Contam., 19:282-302.

13. Schwartz GG. (2002). Hypothesis: Does ochratoxin A cause testicular cancer? Cancer Causes Control. 13:91-100.

14. JECFA (Joint FAO/WHO Expert Committee on Food Additives). (2001). Safety Evaluation of Certain Mycotoxins in Food. WHO Food Additives Series 47; FAO Food and Nutrition Paper 74. 2001. Retrieved August 10, 2008, from: http://www.inchem. org/documents/jecfa/jecmono/v47je01.htm.

15. Curtui V.G., Gareis M., Usleber E., Martlbauer E. (2001). Survey of Romanian slaughtered pigs for the occurrence of mycotoxins ochratoxins A and B, and zearalenone. Food Addit Contam., 18, 730-738.

16. Matrella R., Monaci L., Milillo MA., Palmisano F., Tantillo M.G. (2006). Ochratoxin A determination in paired kidneys and muscle samples from swines slaughtered in southern Italy. Food cont., 117, 14-117.

17. SCF. (1998). Scientific Committee on Food. Opinion on Ochratoxin A. CS/CNTM/MYC/14 final. Annex II to document XXIV/2210/98, European Commission, Brussels,

18. EFSA Journal (2006) 365, $1-56$. Opinion of the Scientific Panel on Contaminants In The Food Chain on a Request from the commission related to Ochratoxin A In Food, Question $N^{\circ}$ EFSA-Q2005-154.

19. Studer-Rohr I., Schlatter J., Dietriech D. (2000). Kinetic parameters and intraindividual fluctuations of ochratoxin A plasma levels in humans. Arch Toxicol., 74, 499-510.

20. Pena A., Seifrtova M., Lino C., Silveira I., \& Solich P. (2006). Estimation of ochratoxin A in Portuguese population: New data on the occurrence in human urine by high performance liquid chromatography with fluorescence detection. Food Chem Toxicol., 44, 1449-1454.

$$
* * * * * * * *
$$

